\title{
WEALTH AND WELFARE.*
}

\section{Chapter III. \\ IMPORTANT ECONOMIC CONCEPTIONS.}

The cases are fortunately few in which it will be necessary to use words in several senses or in a sense widely different from that which they have in popular speech. But whether used in a new sense or an old sense, in one sense or many senses, there is equal need of definiteness and consciousness of our own processes. There is all possible difference between systematic elasticity, and indefiniteness and vagueness. In addition to the important distinction between object and subject, considered in the preceding chapter, a number of important conceptions require analysis before we can safely proceed with our discussion.

The group of words, happiness, pleasure, enjoyment, etc., have not been more fortunate than wealth at the hands of careful writers. We saw that philanthropy and class conflict have had a hand in shaping the definition of wealth. Philosophical controversy has had a hand in defining happiness, which is incomparably worse. The first gives us only the tangle of accident; the second gives us the tangle of planful ingenuity.

Is happiness one thing or more than one? Do happiness and pleasure stand for distinct and inconvertible experiences, or are they but species under a true genus? Is happiness attainable as the result of conscious search, or is it incidental to the pursuit of something else? Into the discussion of these questions we cannot now enter with profit. It is reasonable to hope that our inquiry into the nature of the satisfactions which men derive from their contact with

* Chapters one and two were published in the preceding issue of the ANNaxs. The concluding chapters will appear in the March issue. 
persons and things will throw some light upon these questions, but we will not prejudice our inquiry by needless assumptions. For the present all we need to decide is which of these terms we are going to employ and in what sense.

The terms happiness and pleasure have become relatively specialized and contrasted with each other. Happiness suggests a relatively permanent state of mind and pleasure a temporary and superficial experience. The one is associated with character and virtue, the other with circumstance and indulgence. The familiar definition of happiness in treatises on ethics as "pleasure resulting from right action" gives technical sharpness to this popular distinction. Whatever may be the validity of this distinction, it plainly is not so fundamental as to require us to recognize it at the outset. Underneath the specific difference there is still a generic unity which is artificially obscured by the popular emphasis upon prominent characteristics. When a man enjoys actions and experiences which most men associate with discomfort, his enjoyment is naturally attributed to a predisposing character on his part. His enjoyment is attributable to himself. But if he enjoys what other men enjoy it does not seem peculiar. Attention is directed to the circumstances which are familiar to all as fugitive conditions of enjoyment. Such enjoyment is attributable to circumstances. Of course both explanations ignore that which is common to both and so unemphasized by contrast. No amount of susceptibility in itself creates happiness. Men do not enjoy susceptibility, they enjoy by means of it. Equally, no amount of favoring circumstance can produce enjoyment without some degree of favoring susceptibility. Character enjoyment and circumstance enjoyment are alike dependent on two factors, character and circumstance, which though differing widely in kind and amount, must invariably co-operate. This co-operation of character and circumstance, susceptibility and environment, subjective and 
objective, is fundamental and generic, is precisely the relation we are to consider in the broadest sense. The differences of kind and amount are specific and subordinate. That they may be and often are of the profoundest practical import, I by no means deny and in all relevant connections am eager to affirm, but they are not basal to our inquiry.

What is the generic character for which we seek a name? The one fact which is common to all these experiences is that they are experiences which an individual, knowing their character, would undergo for their own sake. Such a category would exclude many wholesome experiences, which though conducive to ultimate enjoyment, are not in themselves enjoyable; it would also include many experiences which are ruinous in their consequences but enjoyable in themselves. The criterion applies to the experience itself, not to some other which precedes or follows it. It applies equally to all agreeable experiences, no matter how concentrated or diffused.

The terms happiness and pleasure do not ordinarily designate any such inclusive category. They are popular names for species under the genus. We cannot profitably use them, therefore, until we come to discuss these specific differences. The term enjoyment, on the other hand, has acquired no such limiting associations, but is comprehensive in its suggestions and fitted to designate the aggregate of the experiences we are to study. I shall continue to use it in this sense as $I$ have hitherto done.

But this use has one great disadvantage. Enjoyment has no correlative term to express its opposite. We have happiness and misery, pleasure and pain, comfort and discomfort, but no such correlative for enjoyment. Whenever we have no occasion to emphasize this distinction the word may very well stand for both. The term enjoyment would therefore be applied to all agreeable and disagreeable experiences taken together, while all objects would be called enjoyable which in any way affect enjoyment. But the moment we 
wish to distinguish between agreeable and disagreeable experiences we are embarrassed. I have already expressed my aversion for such clumsy phrases as positive enjoyment and negative enjoyment, whose scientific advantages are more than counterbalanced by their literary defects. Of the various correlatives available for this purpose pleasure and pain seem least objectionable. It will be understood therefore that when used as correlatives pleasure and pain are inclusive terms referring respectively to agreeable and disagreeable experiences in general and with no reference to differences between high and low, sensual and spiritual, character and circumstance.

The word consumption has had a most unfortunate experience in economic literature. At least three meanings can be traced, with the usual variations and blendings. It is an open question whether the term has not become radically and incorrigibly misleading, not so much because of its different meanings as because of its inherent unsuitableness for them. Its primary and irrepressible suggestion is that goods are used $u p$. The word was selected at a time when attention was concentrated on goods of which this was conspicuously true. These goods still have undue prominence in the minds of economists. Of course Walker and others have called attention to the fact that goods are not destroyed by use to anything like an equal extent, some not at all, to which may be added that some goods are actually preserved by using and perish by disuse. But still the incident of the process is more prominent than its essence-thanks to this same ill-chosen word. Sometimes the essence is forgotten altogether, as in the recent treatise of Nicholson.

"On the other hand, sometimes the work of consumption is performed by nature altogether against the wishes of the possessor of the commodity. Thus breakwaters, embankments and docks are wasted by the powers of wind and water; buildings crumble away under atmospheric influences; useful plants and animals are destroyed by living plagues; whilst in addition to the accumulated effects of 
slowly-working causes, we have occasional catastrophes through hurricanes, floods and earthquakes."

And this is not the worst. This conception of consumption is at least definite, if not wholly justified, by the etymology of the word. It means destruction, nothing more nor less, and might be dismissed with no other commentary than that the word, destruction, would have been a better name for it. But this same writer mixes this conception inextricably with the other which economists have been striving to associate with the unfortunate term, namely enjoyment or use, thus sanctioning the very confusion which it is so important to avoid. We have small reason to wonder that popular conceptions of economic relations are vague.

The deterioration of goods, either through use, accident or causes inherent in their nature, is a matter of importance in economics as in practical affairs, and one which can not be ignored in a consideration of enjoyment. But to describe this process the word deterioration is as unambiguous as words are apt to be. For that specific kind of deterioration which is incident to use the word consumption is admirably adapted. The deriving of satisfactions from goods is a perfectly distinct process, bearing only a fortuitous relation to the foregoing. For this process, too, we have a number of terms-use, enjoyment, utilization-none of them ideal, but all of them fairly available. But fate has willed that this process should be known as consumption in all recent discussions. It is not without hesitation that I decide to try to stem this current of vicious tendency, but if such an effort is ever worth while it is so here. All principles of terminology demand the change. We are dealing with distinct conceptions which need names, and usage, while piling up words on one of them, leaves the other with no distinctive designation. The use of the word consumption to indicate the enjoyment of goods by processes often involving no consumption at all, is in defiance of an etymology that is visible on the surface and an extensive 
counter usage with its powerful current of suggestion. Even within the technical field where this incongruous meaning has grown up, the original and incompatible meaning has persisted with most mischievous results. So I will venture to excuse the term from its new duties and confine it to its original use. Except when quoted or in references to quotations from other authors, I will use the word only to indicate the destruction of goods incident to their use. This is not necessarily all the destruction which is simultaneous with use, since nature destroys on her own account, a destruction for which use is not responsible. Nor does it necessarily involve a net increase of destruction, for consumption may displace a destruction which would be more serious than itself, or finally there may be no effect, destructive or preservative, in connection with use, in which case consumption is nil. But it is only to this incident of use that the word refers, a distinctly objective phetiomenon as contrasted with enjoyment, which is a subjective phenomenon. 'The generic term for these unfavorable changes in goods is deterioration, of which consumption and destruction are species, the one incident to use and the other independent of it.

The word use is an excellent example of that elasticity of meaning which we have noticed as the characteristic of popular speech and which in this case at least has proved safe and serviceable in scientific discussion. In such expressions as: What is the use of doing that? the use of silk is increasing; the muscles are developed by use, the variety and the definiteness of meaning are both apparent. There seems to be 110 occasion to protest against this free use of the term, but it is desirable to notice the fundamental meaning of the word and its relation to other conceptions which we have considered.

All economic processes are reducible to two, getting good out of things, and putting good into things. The first and more fundamental process is use, the second and subsidiary 
one is production. The good which men are thus busy in getting out and putting into things is usefulness or the power to further our enjoyment, and things which have this good, artificially or naturally, are goods. These goods are of two kinds, final and mediate, the former yielding up their usefulness in the form of enjoyment, the latter passing it on into another good. The former goods are enjoyable, the latter are not, but all are useful. Usefulness is therefore the capacity to produce enjoyment, directly or indirectly; enjoyableness the power to produce it directly. Enjoyableness is therefore a variety of usefulness, the final form into which it passes as the result of its many transformations. Thus we enjoy pictures, but we use paint. The latter does not assume an attractive form which directly contributes to our enjoyment till the painter has used it and produced a picture. The laws of use are therefore closely analogous to the laws of enjoyment, the same laws in fact in wider application.

It will be noted that while use is entirely distinct from production in the case of final goods, it is apparently identical with it in the case of mediate goods or capital. We can not use such goods without producing goods, since by hypothesis that is the only thing they are good for. But after all, the identity of the two is merely apparent. When we use flour we produce, but we do not produce flour; we produce bread. Logically and in their bearing upon a particular good the two processes are fundamentally opposed. To pour wine out of a bottle and into a glass is a single process, but for all that there is a difference between pouring out and pouring in. While therefore use is intimately associated with production, it is never to be confounded with it. It is one aspect of a process which in its other aspect is either production or enjoyment according to the nature of the good.

I have so far avoided the term utility, which is generally regarded as the more scientific synonym for usefulness. So 
far the two terms have not been differentiated, because the two conceptions toward which they severally gravitate have not been clearly distinguished. But it is plain that there are two conceptions and that the word utility, which has been applied to both, has been used in a double sense. The first of these is power to further enjoyment, which I have designated as usefulness. The second is apparent or anticipated power to further enjoyment, which may be conveniently cailed utility. So far as etymology goes this distinction is an arbitrary one, but it is plainly foreshadowed by recent discussion. In all discussions of value and in the definition of value as marginal utility it is this anticipation or estimate of enjoyment which is considered. The distinction is important because anticipation not only differs from realization but it differs from it pretty regularly and in accordance with principles which may be formulated, at least in part. In certain connections, however, this approximate parallelism between the two makes the distinction unimportant. When we consider the relation of utility to any other phenomenon it must be sharply distinguished from usefulness. But if we consider the relation of one kind of utility to another, it makes no difference whether we consider actualities or anticipations. What is true of the one will be true of the other, with slight differences of degree. Wherever relations can be discussed equally well as anticipated or realized it will be convenient to use the term utility without emphasis upon the special meaning here defined. Although standing for the less fundamental of the two conceptions it is the more familiar of the two terms and can be safely used in the more representative sense. 


\section{Chapter IV. \\ ECONOMICS AND EVOLUTION.}

In considering the nature and extent of economic jurisdiction we have so far confined our attention to internal problems. We now turn to the problem of foreign relations. These present somewhat perplexing examples of dependence and independence, joint and rival jurisdiction. The most important of these inquiries is that of the relation of economics to evolution. Economic problems are problems of enjoyment. We have seen that this is the lodestone of all economic impulse, whether recognized or unrecognized, visible or concealed. The problem before us is therefore that of the relation of enjoyment to evolution.

The economist has seldom troubled himself with such an inquiry, has often indeed been conspicuously averse to doing so. And strictly speaking, it is hardly a part of economics. But if he cares more to come to correct conclusions than to be exclusively economic such an inquiry will be profitable. It concerns the main premise of the science and one which has been the subject of persistent fallacies. The study of organic evolution has thrown much light upon the origin, nature and limitations of the impulse to enjoyment, and in assuming it as the starting-point of economic inquiry it is well to know what we are assuming. In revising the premises of our science we have much to gain by a careful study of the laws of evolution, the process to which all the phenomena with which we deal owe their existence. Impulses and energies must be understood in their largest relations if they are to be made the basis of sound conclusions. This is a very different thing from merely translating economics into the language of biology under the plea of making it an evolutionary science.

One of the most persistent obstacles to an understanding of this relation is the assumption that enjoyment (happiness) is the purpose of evolution, or in older phrase, the 
purpose of nature or of creation. The assumption that nature goes about her work knowingly and has an eye to the satisfaction to be gotten out of her work is so instinctive and universal that it has governed the development of language so that we can not speak of nature without seeming to subscribe to the theory. Such an assumption would be profoundly significant if it were not the obvious result of our limitations rather than of our insight. We naturally explain the unfamiliar by the familiar, the actions of others by our own, the activities of nature by the activities of men. The echo is supposed to be somebody speaking; actions are regarded as malign which would have been malign had we committed them. The process is valid enough, but with the meagre data of individual experience, its conciusions are often false. There are few better tests of culture than the ability to escape from the provincialism of iudividual experience. In accord with this tendency the savage peoples his little world with ghostly agents; Ulysses, baffled by storms, attributes the hindrance to the anger of Neptune, and the philosopher, noticing adaptations in nature with little attention to the changes that produce them, reverts to the same ready explanation of personal purpose. In all these explanations we can discern the reasonings of men too absorbed in their own activities and disproportionately conscious of the causes which emanate from their own minds.

By a slow but wholesome process, exceedingly wholesome in its reaction on human conduct, nature is exonerated from the motives thus attributed to her specific acts. Storms become impersonal and men build breakwaters instead of altars to Neptune. Disease is attributed to bacteria instead of demons and inoculation takes the place of incantation. The attribution of purpose retreats from the specific to the general. It is there that we encounter it as the assumption that the purpose of evolution is enjoyment, that this is the 
goal toward which the whole movement has from the first been and still is intentionally directed.

I am far from asserting that this assumption is false, but it is certainly premature. We know all too little of the direction of evolution in its various stages and are still too ignorant of what it has accomplished in the way of conscious happiness to warrant so sweeping a conclusion. The most that we can confidently assert is that force is not in equilibrium, that change is constant, and that for a long time back this change has been in the direction of increasing complexity of organic life; that finally, pleasure and pain are familiar experiences to higher organisms and bear to each other an uncertain proportion, whether favorable or unfavorable, constant or changing in the aggregate we can not say. Avoiding, therefore, any such dangerous working hypothesis as this, we have simply to observe the circumstances under which enjoyment appears and the rôle which it plays in the evolution of organic life. Why has life developed the power of feeling pleasure and pain? What function do these experiences perform?

The general law of organic evolution is familiar. There is reproduction in geometric ratio, (quite inevitably) overcrowding, struggle for existence and natural selection or survival of the fittest. The result is an increasing adaptation of the organism to its environment. If the environment itself were fixed the adaptation would become complete and the species would have an absolute hold on life. But as the environment itself is subject to change, and as the rate and direction of the change in the two cases may not be the same, the evolving organism may run a losing race and eventually be ruled off the field. How is this process affected by the susceptibility to pleasure and pain?

An organism that knows nothing of evolution and is oblivious of remoter consequences will do its best to secure pleasure and avoid pain. But it does not follow that because the organism seeks enjoyment nature will co-operate to that 
end. An individual may conceivably enjoy things which are detrimental to him, in which case nature may mark him for extinction instead of furthering his desires. Pleasures are not necessarily profitable experiences and any amount of divergence is possible between the desires of an organism and the necessities of its existence.

Yet in the long run pleasures and pains tend to identify themselves with profitable and unprofitable experiences, respectively, or rather, there is a tendency for those experiences, and only those experiences which are favorable to existence to become pleasurable. If we introduce into a sheep pasture a plant which is injurious to sheep and different from any with which the sheep are familiar, there is likely to be at first a difference of taste regarding it on the part of the sheep. Some will like it and some will not. Eventually, as the result, it may be, of a heavy mortality among the sheep, all will come to dislike and avoid the noxious plant, not so much because of any observation of its consequences as because the plant will have sorted the sheep and eliminated those with unfortunate predilections. Thus conduct unfavorable to life becomes associated with disagreeableness or pain. In the same manner experiences favorable to life become associated with pleasure, not because there is any necessary or predetermined relation of this kind, but because only those species can permanently exist whose members establish such a relation.

This seems at first sight to point to the conclusion already referred to that enjoyment is the end of evolution, but such a conclusion is subject to serious qualifications. Aside from the fact that evolution encourages pleasure apparently as a means rather than as an end, there is the farther and more serious fact that pain is developed and used in precisely the same way. The two seem to serve a similar purpose and to be employed by nature in no fixed proportion. Whether she rewards the necessary act or punishes its neglect, it is likely to be performed in either case if the connection is 
perceived and the incentive sufficient. Doubtless the one line of incentive is better adapted to certain cases than the other, but we can discern no fixed necessity calling for an increased proportion of pleasure as evolution proceeds.

In the second place, evolution does not assure increasing adjustment, only a constant tendency toward it on the part of the organism. Lesson after lesson may be leartued and the proper adjustment established between profit and pleasure, and still the lessons to be learned may be more numerous and perplexing than before. There may be more perilous pleasures and more ambiguous pains than at an earlier period, all because the environment to which the species is trying to adapt itself, will not stay fixed, but goes on changing under the pressure of forces which have no regard for these adaptations.

Finally, changes in the environment may make previous adjustments into misadjustments and thus give the lie to their associated pleasures and pains. A line of action which has long been profitable and so has become uniformly pleasurable by selection, may become by a change of circumsiances unprofitable and dangerous, while still for a long time its pleasurableness persists. This is peculiarly true of the human species in its relatively recent social evolution. Countless centuries of organic evolution have established instincts and pleasures useful in a pre-social state, but inimical to associate life. The most poignant of our miseries are connected with this painful undoing of nature's amazingly perfect work. These social requirements are but an extreme example of what is continually taking place, a change in environment requiring new or even contrary adjustments. If such a change is more rapid than the adaptive changes in the organism, the adjustment between pleasure and pain on the one hand and wholesomeness on the other, becomes less perfect, and for a time we have retrogression, a decrease in enjoyment and a lower general vitality in the species. Periods of retrogressive evolution 
or decreasing adaptation seem to be unfavorable to enjoyment and the same is apparently true of all periods of extensive readjustment. In periods of relative quiescence the species seems to enjoy with less discount the fruits of hardwon adaptation, but even here the good of pain is not absent nor the pleasure of life unmixed. We can not assume that there is any force outside the individual which tends irresistibly to secure a preponderance of pleasures over pains in his experience.

We have now to consider what opportunity is granted to the individual by this all-enveloping process to work out his own enjoyment. For the individual knows nothing of evolution and its ends, as evolution knows nothing of him and his. He prefers the enjoyable as uniformly as nature prefers the livable. That his preference must be subordinate to hers is plain, for if he chooses the inadmissible he will not live to do much choosing. Nature seems not to have created man with any intention of making him happy or making him miserable, but those whose inclinations and aversions are such as to impel them along the straight and narrow path that leads to life, these persist and perpetuate their type and their inclinations.

So far as the foregoing considerations have to do with the problem of survival they are apart from the problem of economics which is concerned with enjoyment rather than with life. To this problem we must now more definitely turn. What bearing bas this subordination of enjoyment to vital interests upou our study of the laws of enjoyment?

In the first place this general subordination of enjoyment to vital interests is in itself the fundamental law of enjoyment, one which limits all others. It is thus the main premise of our science. Every tendency to pleasure is sure sooner or later to encounter the inexorable requirements of life and to suffer subordination or annihilation as a result. This inevitable encounter is of interest alike to the study of 
enjoyment and to the study of life. We have not completed the life history of an enjoyment until we have followed it to this critical point and discovered what becomes of it. To study subordinate phenomena and ignore their subordination is misleading in both theory and practice. We lose sight of the co-ordinating principle and open the way to all manner of baseless assumptions. In the present connection we also lend countenance to mischievous fallacies in practice. The notion that all enjoyments are matters of taste and that one man's taste is as valid as another's, while not without a certain limited justification, is troublesomely prominent in popular thought. But what has economics to say against such a notion if it ignores the ultimate subordination of enjoyment to vital interests, that is, its functional character in the evolution of the species? We need not be disturbed by the temporary moral consequences of scientific inquiry, but we may well have a concern for the moral consequences of unscientific inquiry. This is our main premise: Enjoyment is the servant of life.

But is this serviceable pleasure the only enjoyment to which man may attain? Such an assumption would poorly account for the phenomena of life as we now see it. In spite of the inexorableness of nature's processes, there is in them much of alternative, much of elasticity. Some things man must do or forbear doing on pain of death, but there are many more which he may do or not as he likes. Eating is a necessity to which man is impelled somewhat by the promise of pleasure, more by the threat of pain. But gastronomy is not a necessity. It is man's deliberate effort to enhance the feeble pleasure of eating. Nature looks on indifferent at man's manipulation of his surplus resources, knowing full well that whether he succeed much or little, sufficient incentives will remain for the accomplishment of her necessary purpose. Man is equally concerned to lessen the pain which constantly attends upon nature's requirements. The numberless pitfalls in man's primitive 
environment are avoided only by the admonitions of nature, which are more or less painful in their working. Man undertakes extensive modifications, which by removing the pitfalls make the admonitions unnecessary. Thus ali the way from the growing of seedless grapes and thornless roses to the blasting of Hell-Gate the pain-destroying process goes on, nature not forbidding till by an unlucky venture some pain is removed which guards an interest or some pleasure devised which betrays him whom it tempts. Then, again, remorseless nature intervenes with her Draconian penalty. Thus eating is required, gastronomy permitted, gluttony forbidden.

Man is thus permitted to achieve for hirnself a happiness to which the process of evolution is indifferent and which it does not assure. He exploits the neutral territory, not without danger, for to trespass beyond its uncertain boundaries is death. It remains to note that this neutral territory is perhaps an enlarging one. As man acquires power over nature and masters her secrets he finds new ways of meeting her requirements with less of risk and pain. More of marginal resource, more time and strength, are thus available for his chosen purpose. The requirement to eat is as imperative as ever, but a requirement which once took all his time and strength now takes but a small part of it. The rest is free for activities before impossible. Doubtless these activities tend to become essential in turn, if not for physiological, at least for social reasons which are not less imperative for the perpetuation of the individual living under social conditions, but this takes time, and such pleasures remain often for a long time functionless and self-justifying. Dangerous pleasures, too, are handled with more skill in the light of greater knowledge. Gastronomy has greater possibilities than before without lapsing into gluttony. The range of territory which may be exploited in the interest of enjoyment is thus extended. Though it is constantly encroached upon by the growing requirements of life, it is 
as constantly enlarged by the exploring pleasure interests. This neutral territory is thus a shifting but a perpetual fact.

Specific pleasures after a probationary period acquire a definitely favorable or unfavorable character, but in a progressive evolution there are always pleasures on probation. These probationary enjoyments constitute a second and important part of our subject. They are of the profoundest importance to the problem of survival, since from them are recruited the ultimate forces that make for or against life. They determine, too, which of many alternative paths life will follow in its growth and the kind of necessities which it will develop. But for the time at least this territory is one of relative freedom for the exploiting interests.

These neutral pleasures are not necessarily higher or lowe than others, as these terms are commonly used, but are intimately associated with pleasures of every order. No illustration can be given which is not purely relative. Eating is the most mandatory of obligations, but the eating of an orange to one who has an unimpaired digestion may not affect in the slightest degree the chances of survival, either of himself or his posterity. Like illustrations may be found in the intellectual and emotional spheres. There is apparently no form of human activity which may not under certain conditions have this neutral character as regards vital interests.

In contrast with these neutral pleasures and pains whose character is sufficiently plain, stand those already described as guarding interests which affect the existence of the individual and the species. These, which may be appropriately designated as vital pleasures and pains, present variations and complications which have occasioned much confusion in economic inquiry. In spite, therefore, of their subordinate character, we can not profitably postpone their consideration. We can best get at the problem by means of an illustration.

Picking my way absent-mindedly across a muddy street, 


\section{Annals of the American Academy.}

I am suddenly apprised that a runaway team is almost upon me. With a frantic effort I escape the whirlwind that sweeps past me and stand exhausted and trembling with the awful terror, from which it takes me some time to recover. But after a while I meet danger in a new form and my conduct is strangely inconsistent. The physician tells me that certain ominous symptoms imply over-work or ill-regulated life and prescribes rest or dieting as imperatively necessary. I almost resent the information and the advice. My action instead of being instant and strenuous is probably both grudging and ineffectual. Similar contrasts are manifest in the eating of food. The starving man eats the most indifferent food with frantic eagerness, while the normal individual gets from dainties only a finite satisfaction.

In recent discussions of utility these facts have been obviously embarrassing. The intense eagerness with which the first few mouthfuls of food are eaten after a long fast had to be accounted for. As it seemed to be out of proportion to the immediate pleasure of eating, the utilitarian has usually fallen back on one of those pseudo-explanations which always stand ready to relieve embarrassment. These first mouthfuls furnish infinite satisfaction because they are the condition of life itself. Farther eating is pleasant, but nowise necessary; so we get less pleasure from it. The general acceptance of this explanation is surprising, in view of the obvious objections to which it is open. It certainly speaks poorly for the power of psychological observation which has been at the disposal of economics.

First of all, whatever may be the net advantage of living, it is not infinite. It may even be nil or less. If the morsel of food which keeps a man from starving assures him all the pleasures which after-life can furnish, it just as certainly assures all the pains which after-life involves. Whatever the balance between these two may be, it is not the principal determinant of men's action. Our illustration makes this clear. In the first place, the same man acts differently 
under different circumstances in defence of the same interest. A sudden menace to his life produces energetic action; a slow one, weak and ineffectual action. If the action is naturally less frantic in the second case than in the first it remains to be explained why it is less willing and effectual. On the other hand, men act alike who estimate the value of life very differently. The suicide planning his own destruction will dodge a bullet or flee from sudden peril quite as effectually as the exuberant optimist. The man who insists that life is not worth living may be an exceptionally anxious observer of his own physical symptoms.

In the second place, it is clear from these same considerations that whatever may be the net value of life, men do not calculate that value before they dodge a runaway or begin to take medicine. Indeed such calculations tend rather to weaken than to reinforce their efforts, for the instinct of self-preservation acts most vigorously in creatures which are incapable of making such calculations. The value of life is therefore in no constant proportion to the effort which is put forth to preserve it, and if it were, the organism would not know it or act in deference to it.

But if these efforts are not to be explained as motived by the pleasure of living, can they be explained by any reference to pleasures or pains? Patten, the most acute of recent writers on this subject, seems to think that they can not. He distinguishes between "absolute" and "positive" utility. Absolute utility is the capacity which a good has of maintaining life. Absolute utilities take precedence of all other considerations, no matter how important, by virtue of their paramount necessity. "No matter how great a sum of satisfaction is sacrificed, these absolute utilities must be secured." "Life is precious and we are willing to sacrifice other ends to preserve it"' (a statement which unconsciously involves the theory which we have mentioned and which Patten rejects). "In contrast with these absolute utilities, 
positive utilities refer, not to life, but to the content of life; they are the sum of satisfactions that can be added to a bare living." From these and other passages it is plainly to be inferred, though nowhere explicitly stated, that the first increments of a commodity used produce a particular kind of result which demands full precedence of the other result. This primary result once accomplished and out of the way, a new kind of use begins which produces a result which did not in any degree follow from the earlier use. Patten does not indeed draw the line so sharply, but his words necessitate the inference we have drawn. In the interest of clearness it is to be regretted that the matter was left to inference. But postponing for the present the question of the order or combination in which these utilities appear, let us inquire whether they are, after all, so radically different. Different, they certainly are, but are they so different that one impulse is referable to pleasure instincts and the other not?

We have seen the fallacy of trying to completely identify these impulses. It involves an ingenious philosophy of life resting on reasons which the individual never thought of and motives which he does not feel. The starving man not only makes no calculation as to the net value of life, but there is no telling what his conclusion would be if he did. If all the good of after-living is contained in a morsel of food, all the pain of living is wrapped up in it, too. The sweet may entice us, but the mixture of bitter and sweet is of doubtful attraction. And even when the food is eaten and life assured, all its good things remain to be paid for at much their full value. Why pay an infinite price for the food which only assures us the privilege of making farther purchases? I am not trying to prove the futility of living, but rather to prove the futility of such calculations as are here presupposed. The agonizing struggle for existence could not be accounted for by any such calculus of pleasures if there were one; but there is not. The great majority of 
mankind live on by default, asking no questions as to the aggregate profit of the transaction.

But if the preservative impulses can not be explained by reference to the pleasure of living, either present or prospective, have they no relation to pleasures and pains? Must we assume them to be absolute, i. e., inexplicable? I am surprised that the alternative explanation has not commended itself to writers on this subject, the more so as it is confrmed by unmistakable experience. The impulse to escape sudden danger is not a struggle for pleasure; it is a recoil from an awful terror which nature has evolved in all species as a condition of their existence and which, while it lasts, is the most terrible of all agonies. The enormous value of the means to that escape as of a plank to a drowning man, is due, not to the exceeding joy of living, but to the terrible pain of dying, which this means enables us to escape.

If we could consider calmly all that is involved in the two alternatives of living and dying, we might act very differently. To live is too often to suffer, and after all, the dying must come. As a mere matter of advantage, therefore, why should a man flee-it may be ignobly-from the peril of sudden death to the prospect of living unhappily and dying with lingering disease? But when confronted by sudden danger we can not figure things out like this. Present pleasures and pains necessarily occupy the foreground of consciousness, and if they are very near they hide all else from view. On the other hand, when the danger is remote and we have an opportunity to compare and estimate advantages, we do make just such calculations, and our action is correspondingly uncertain and inefficient.

These same principles hold true of preservative pleasures, but the extremes are less marked. No appetite, at least in man, acts with the suddenness and intensity of the dread of death, unless it be in those extreme cases where again the 
motive is pain rather than pleasure. But who has not known the experience that present pleasures have been inordinately tempting and have subordinated considerations of prudence to a degree inexplicable in moments of later reflection?

The conclusion of all this is so obvious that it may seem to have been unwarrantably deferred. Vital pleasures and pains, though more intense and urgent than others, involve no new principle. The most intense instinct, like the most far-reaching plan or the feeblest inclination, is but a phase of the universal recoil from suffering and attraction toward enjoyment. The intensity of this recoil or attraction is determined, not by the intensity of the ultimate experiences, but by the vividness with which they are anticipated at the moment in question, a fact that explains many apparent inconsistencies. Incidentally it is of interest to note that the more intense preservative instincts are based on pain stimuli rather than on pleasure stimuli. Their gratification involves no infinite satisfaction, indeed no positive satisfaction at all, a fact abundantly attested by experience. Ii it involved the infinite satisfaction so often assumed, the ideal condition of life would be to live in continual peril or on the verge of starvation.

There are not two kinds of utility, therefore, but one. When we include pain in our calculations we are quite able to explain why a few morsels of food may at times have such an extraordinary value without imagining computations which nobody makes or presupposing any inexplicable impulses. We have now to note that this "infinite value of the first increment" is ordinarily a pure fiction. The pleasure derived from the first mouthfuls of one's dinner is nothing so very considerable. If they exorcise the spectre of famine they may indeed be precious, but ordinarily there is no such spectre to be exorcised. Only in the rarest cases have the earlier increments of consumption any such exaggerated importance. On any such supposition 
computations of total utility all figure up to infinity. Not only is food of infinite utility, since it saves men from starving, but as planks may save men from drowning, there must be an infinite utility for planks. Economics becomes a bewildering computation of infinities. But the opportunity to render such extraordinary services is fortunately rare. The ordinary loaf or plank, even though it be the first of its kind, has but a commonplace opportunity. It is a travesty on experience to assume that the first morsels of an ordinary dinner have an incalculable utility to a person who never got wholesomely hungry in his life.

It will be useful to recall briefly the conclusions reached in this chapter. We have seen that enjoyment in its double form of pleasure and pain is not an accident or an arbitrary addition to life, but a means to its preservation and development. Its function is to incite to wholesome and deter from unwholesome action, a function which it is ultimately constrained to perform. But while pleasures tend to become identified with wholesome experiences and pains with those that are unwholesome, there are at all times pleasures which have not acquired such associations or in which these associations have become obsolete or even reversed. There are therefore inandatory, neutral and forbidden pleasures, and monitory, neutral and obligatory pains. The more urgent interests, especially those of self-preservation, are in general entrusted to the protection of monitory pains; the less urgent, including those of procreation, are secured by mandatory pleasures or appetites. Forbidden pleasures and obligatory pains are in general survivals of conditions which have disappeared, or they are the product of disturbances in settled adjustments due to the appearance of new interests. Pleasures and pains which are closely associated with vital interests can not be consciously manipulated with any profit. Human enjoyment, so far as it depends upon these, can be modified only by modifying individuals so as to bring them into harmony with nature's requirements. This can be 
temporarily accomplished by education, the encouragement or repression of tastes as need may require, but its permanent accomplishment must depend, we are constrained to believe, principally upon the efficiency of natural and social selection, a process to which as yet our conscious efforts lend but doubtful assistance. With this process, conscious or unconscious, we are not at present concerned, save in so far as its consideration is inseparable from enjoyment. It is the subject of a distinct study.

Neutral pleasures and pains, those not yet drafted into the service of vital interests, or those that have been set free from that service, those indeed which, like eating, are charged with important functions, but have a certain margin of freedom at their disposal, these may be legitimately manipulated in the interest of immediate enjoyment. Of course the enjoyments which economics must consider are not confined to those which vital interests would pronounce legitimate. Prohibited pleasures are feverishly pursued and monitory pains are deadened with opiates, but these manipulations are ephemeral. There is not and can not be any permanent tampering with vital interests. These enjoyments, whether legitimate or illegitimate, wholesome or nuwholesome, are the subject of our present study. Taken in connection with the activities to which they give rise they are the subject of economics.

H. H. POWERS. 